\title{
AIAA 98-2421 \\ An Overview of Recent Developments in Computational Aeroelasticity
}

Robert M. Bennett and John W. Edwards NASA Langley Research Center Hampton, VA

\section{$29^{\text {th }}$ AIAA Fluid Dynamics Conference June 15-18, 1998 / Albuquerque, NM}


AIAA-98-2421

\title{
An Overview of Recent Developments in Computational Aeroelasticity
}

\author{
by \\ Robert M. Bennett \\ Senior Research Engineer \\ Associate Fellow, AIAA \\ John W. Edwards \\ Senior Research Scientist \\ Associate Fellow, AIAA \\ Aeroelasticity Branch, Structures Division \\ NASA Langley Research Center \\ Hampton, VA 23681-2199
}

\begin{abstract}
$\underline{\text { ABSTRACT }}$
The motivation for Computational Aeroelasticity (CA) and the elements of one type of the analysis or simulation process are briefly reviewed. The need for streamlining and improving the overall process to reduce elapsed time and improve overall accuracy is discussed Further effort is needed to establish the credibility of the methodology, obtain experience, and to incorporate the experience base to simplify the method for future use. Experience with the application of a variety of Computational Aeroelasticity programs is summarized for the transonic flutter of two wings, the AGARD 445.6 wing and a typical business jet wing. There is a compelling need for a broad range of additional flutter test cases for further comparisons. Some existing data sets that may offer CA challenges are presented.
\end{abstract}

\section{$\underline{\text { INTRODUCTION }}$}

One troublesome area for aeroelastic analysis has been the transonic speed range. Shock waves that occur in the flow over wings and bodies are not included in conventional linear theories. Furthermore, minimum flutter speeds, buffeting, limit-cycle-oscillations (LCO), aileron buzz, and shock-boundary layer oscillations may be encountered. Computational Fluid

Copyright (C) 1998 by the American Institute of Aeronautics and Astronautics, Inc. No copyright is asserted in the United States under Title 17, U.S. Code. The U.S. Government has a royalty-free license to exercise all rights under the copyright claimed herein for Governmental Purposes. All other rights are reserved by the copyright owner.
Dynamic (CFD) methods have been extensively developed and applied in the area of steady aerodynamics in the past 2-3 decades. Application of this methodology for unsteady aerodynamics to be used in aeroelastic analyses has also been under development. When CFD is coupled with the structural dynamics in the computational process, it is generally referred to as Computational Aeroelasticity (CA). One of the difficulties with $\mathrm{CA}$ is that aircraft must be cleared for flutter significantly beyond cruise conditions where strong shocks, separated boundary layers, and other flow conditions which are difficult to compute, may be encountered.

In the past, CA has required long solution times on expensive supercomputers. Thus, the associated costs were very large. However, in the past decade, workstation-type machines have attained the performance level of the supercomputers of the previous decade and the cost of the computation has decreased by between two and three orders of magnitude. Nevertheless, the cost of labor, elapsed time, and peripheral processing is still significant. The technology has evolved to the status that it can be used for analyses to check cases that might be considered critical based on linear analysis. However for multidisciplinary design problems which can involve as many as $10^{5}$ to $10^{6}$ evaluations of the flutter eigenvalue matrix for stability, CA is impractical without further development of innovative methods of application. This paper will review one approach to an aeroelastic analysis process with some comments on possible improvements. Some CA results will be discussed for 
AIAA-98-2421

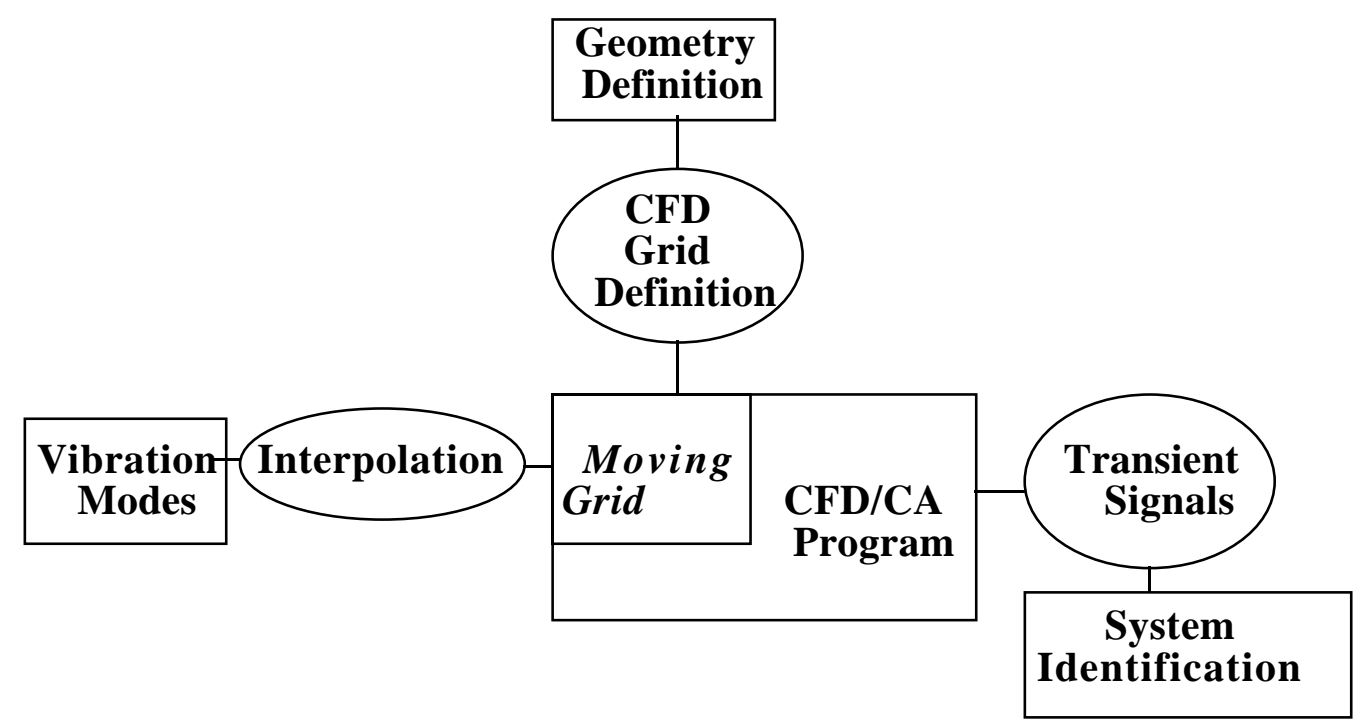

Fig. 1 Computational Aeroelasticity analysis block diagram for time-domain analysis.

two wings, the AGARD 445.6 wing and a typical business jet. The oscillatory shock-boundary layer oscillation phenomenon will also be highlighted and some possible challenges for the $\mathrm{CA}$ researchers to consider are presented.

\section{OVERVIEW OF ONE CA ANALYSIS PROCESS}

One approach to computational aeroelastic analysis is depicted by the block diagram of Fig. 1. This illustrates a time-domain approach based on representing the structural dynamics with vibration modes. As indicated in the Introduction, emphasis should be placed on making the entire process more efficient. In this section some overall comments are given on the CA procedures in use at the Aeroelasticity Branch of the NASA Langley Research Center (LaRC). Similar approaches at other organizations are presented in refs. 1-3.

In the Aeroelasticity Branch there are several CFD codes in use. At the transonic small disturbance level, the in-house developed code CAP-TSD ${ }^{4}$ (Computational Aeroelasticity Program - Transonic Small Disturbance) is used. Also viscous effects can be considered with a stripwise, inverse boundary layer code incorporated in CAP-TSD by Edwards ${ }^{5}$ and called CAP-TSDV. Codes at the Euler and Navier-Stokes level are the CFL3D ${ }^{6}$ code developed by the Aerodynamic and Acoustic Methods Branch at LaRC, and ENS3DAE ${ }^{7}$ which was developed at LockheedMartin under Air Force sponsorship.

The three major elements of most CA methods involve preprocessing of the geometry and modal data, the execution of the CFD computer program, and the postprocessing of the output data. Of course at all stages of the process, plotting and monitoring of all data is essential both for assuring that the data are error free, and that the results are properly converged. The plotting and monitoring tasks can be very time consuming and a high level of automation is desired.

For mode processing which requires interpolation from the vibration-modal grid to the aerodynamic grid, we have generally used the surface spline. ${ }^{8}$ For the small disturbance code that requires modal slopes as well as amplitudes, some of the limitations of this spline can be overcome for cases using calculated vibration modes by splining the modal rotations rather than using the 
slope of the spline. ${ }^{9}$ This capability is basically developed for wings only. The development of a suitable method for including fuselage or bodies may require significant effort. An evaluation of this technology is given in ref. 10 .

Geometry processing is usually treated on a case-bycase basis, and can range from a simple spline for airfoils to a more elegant Computer-Aided-Design model (CAD). The TSD methodology also requires slopes, which demands particular care. The significant task is in grid generation for the CFD portion of the process. With TSD codes, the task can be built into a short interactive program making use of experience. For the higher equation level codes the grid generation is more complex and requires a significant level of user skill.

For the TSD codes, the surface velocity boundary condition is applied at a mean plane and thus the grid does not have to be moved with the deforming surface. However, at the Euler and Navier-Stokes level, the grid must move with the surface. Normally this is done with some type of deforming mesh algorithm. There are several types in use, such as a spring analogy, ${ }^{11}$ simple shearing, ${ }^{7}$ or more complex deforming algorithms exemplified by the complex multi-block case of ref. 12. Deforming meshes can be difficult as in certain cases the mesh can fold over on itself creating a negative computational cell volume and program failure. Also some algorithms require a significant increase in memory and CPU time over the basic CFD code. This is an active research topic at the present time.

For this type of problem, CPU speed, algorithm efficiency, and parallel processing to decrease turnaround time are essential. The rule of thumb developed in some of the early CA flutter analyses is that it takes about 100 runs to calculate a flutter boundary for several Mach numbers and dynamic pressures using time simulation. This would include runs for static initial conditions, debugging, and dynamic response.

For post processing of output time domain signals for linearized stability, the damped sine wave fitting procedure of ref. 13 has been extensively used. It is limited to analyzing a single modal coordinate and to a low number of modes in the fit, usually about six. Other methods have been developed along the lines of ref 14. In addition, some initial trials of the system identification of ref. 15, which is incorporated in the commercial program of ref. 16, appear quite promising. For low amplitude stability assessment, the record length requirements of the system identification method dictates the length of the computer run and is a strong driver on computer time.

It might be noted that for symmetric motions only a half airplane needs to be treated by CA methods. However for antisymmetric motions, the full airplane must be treated thus doubling the memory and CPU requirements. ${ }^{17}$ Furthermore, both symmetric and antisymmetric modes must be retained in the analysis because the static aeroelastic deformation for the initial condition involves the symmetric modes. The cost of the dynamic analysis is thus doubled as well unless there is special treatment of the deformed shape.

The CA methodology requires both a reasonable appreciation of the CFD technology and of aeroelasticity. Generally it has been found to work best with a teaming approach.

\section{VERIFICATION}

Unfortunately it is relatively easy even for an experienced user to run CA programs and generate reasonable looking results that may not be accurate. This puts a burden on the user and developer to verify both the program and the results. A recent issue of the AIAA Journal contains a 100-page section on credible CFD calculations ${ }^{18-29}$ with emphasis on separating the issues such as grid convergence, residual convergence, algorithm convergence, and program correctness. Unfortunately, in the quest for time accuracy verification, there are very few test cases other than one-dimensional shock problems and one-dimensional wave propagation problems. With a TSD code it is relatively easy to revert back to linear theory for comparison, whereas gridding issues make it more complex for the higher level codes. Generally it is preferable to start a flutter analysis by verifying a result obtained from linear theory.

Comparisons with experiment are essential for verification, but agreement with experiment does not in itself serve as complete program verification. Bobbitt $^{30}$ has discussed the CFD validation process and listed ten items in each of the experimental and CFD areas that may affect the outcome of comparisons. The list was primarily oriented toward static results. For dynamic or flutter cases, modal accuracy and completeness becomes a further factor. In addition flutter conditions measured in a wind tunnel are usually 
are a judgment call by the investigator and should not be interpreted in the same sense usually inferred for static wind tunnel measurements. Striving for exact agreement between theory and experiment is futile. Sometimes there can be systematic errors such as indicated by one case of a comparative tunnel tests for unsteady data that surfaced an unusual effect of a root sidewall porosity that might not have been detected without the other tests. 31

\section{$\underline{\text { AEROELASTIC TEST CASES }}$}

As previously mentioned, an essential part of the verification process is the availability of good experimental data for test cases. One flutter test case that is publicly available with enough information for CA application is the 445.6 wing $^{32}$ which is known as AGARD Configuration I for which our results will be subsequently discussed. This configuration has been extensively used for computational studies. A limited survey yielded 15-20 different investigations using this data. Although it has been over ten years since this data set was made available, there is still no Configuration II. Many of the flutter data sets do not have adequate information for geometry or adequate modal information for benchmark calculations. Some efforts have been made in the LaRC Benchmark Models Program $^{33}$ where the data are for simple planforms only. During these tests, significant effort was placed on measuring unsteady pressures during flutter. Some of the results will be discussed in a later section.

Another approach is to try to calibrate the unsteady aerodynamics separately, by measuring unsteady pressures and/or forces during forced oscillations such as pitch, plunge, or control surface oscillations. There is a wide range of data available for this purpose. One notable effort by AGARD resulted in an organized set of test cases for several two and three-dimensional configurations and are published in ref. 34-35. These cases have been widely used for evaluating unsteady aerodynamics. There is currently an effort to assemble another set of cases and another document by a Working Group under the Applied Vehicle Technology Panel of Research and Technology Organization (formerly AGARD). These cases will also include cavity flows, dynamic stall, vortex flows, as well as flutter-oriented data sets. Publication is expected in the latter part of 1999 .

One of the difficulties with just looking at unsteady aerodynamic comparisons is that it is difficult to interpret the effect of imperfect agreement of pressures on aeroelastic problems. That is, how much change in flutter velocity would be produced by a deviation in pressure at a point on the wing? For example, one would normally expect more aeroelastic effects from deviations at the tip than otherwise, but each case must be treated individually. Technically this is a flutter sensitivity problem which is straightforward for a specific case, but it is not generally investigated.

There is a general need for flutter test cases for a variety of configurations for further validation efforts. Further efforts in collecting and organizing existing data sets is needed, and further tests for this purpose need to carried out.

\section{REVIEW OF SOME RECENT RESULTS}

The results for two flutter test cases are presented. The results are mostly those generated by the Aeroelasticity Branch and also have been presented in ref. 36-37. The flutter stability boundaries are presented in terms of flutter speed index, which is the flutter velocity divided by the root semichord and the square root of the mass ratio, and the frequency ratio which is the flutter frequency divided by the torsional frequency.

\section{$\underline{445.6 \text { Wings }}$}

The 445.6 wing planform is shown in Fig. 2. There were several of these semispan models which were cantilevered from the wind tunnel side wall and had a

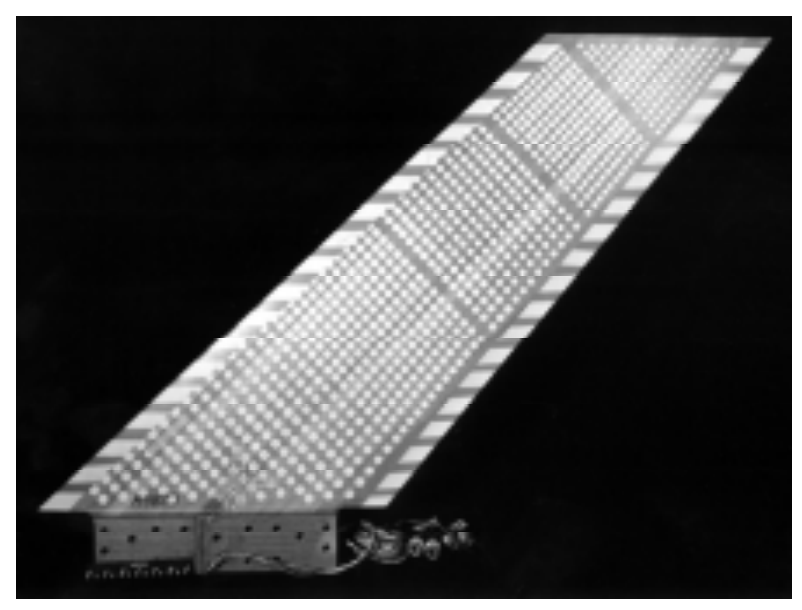

Fig. 2 Planview of AGARD Wing 445.6 Standard Aeroelastic Configuration 
quarter-chord sweep angle of $45 \mathrm{deg}$ (leading edge sweep of $46.3 \mathrm{deg}$ ), a panel aspect ratio of 1.65 , and a taper ratio of 0.66 . This series of wings was flutter tested both in air and in heavy gas in the Transonic Dynamics Tunnel (TDT) at the NASA Langley Research Center.

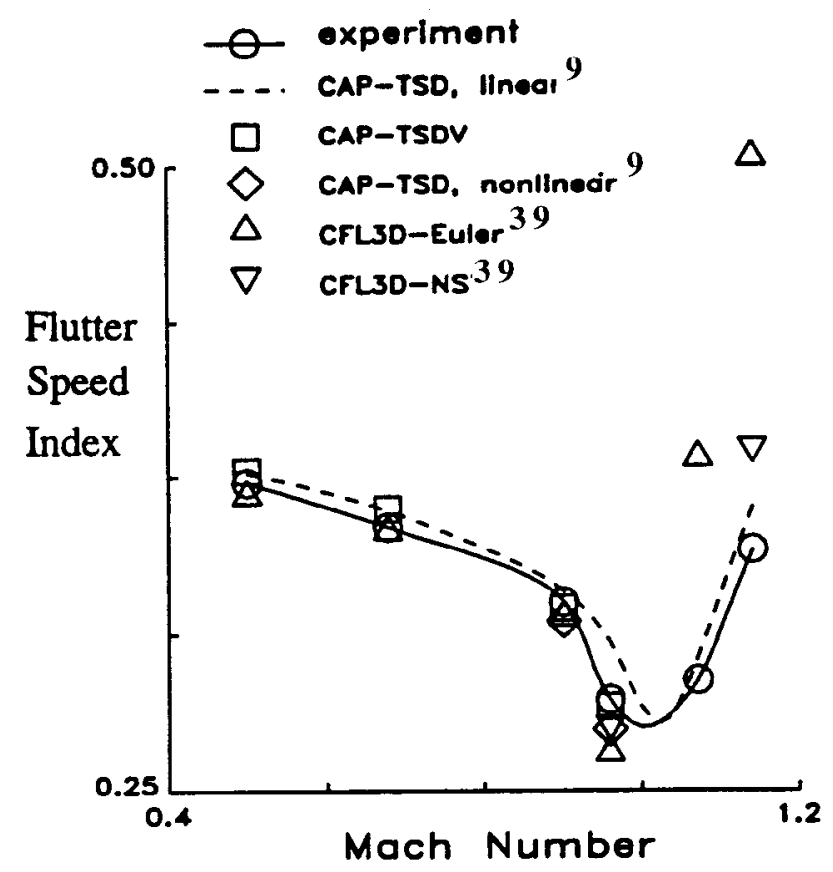

(a) Flutter speed index.

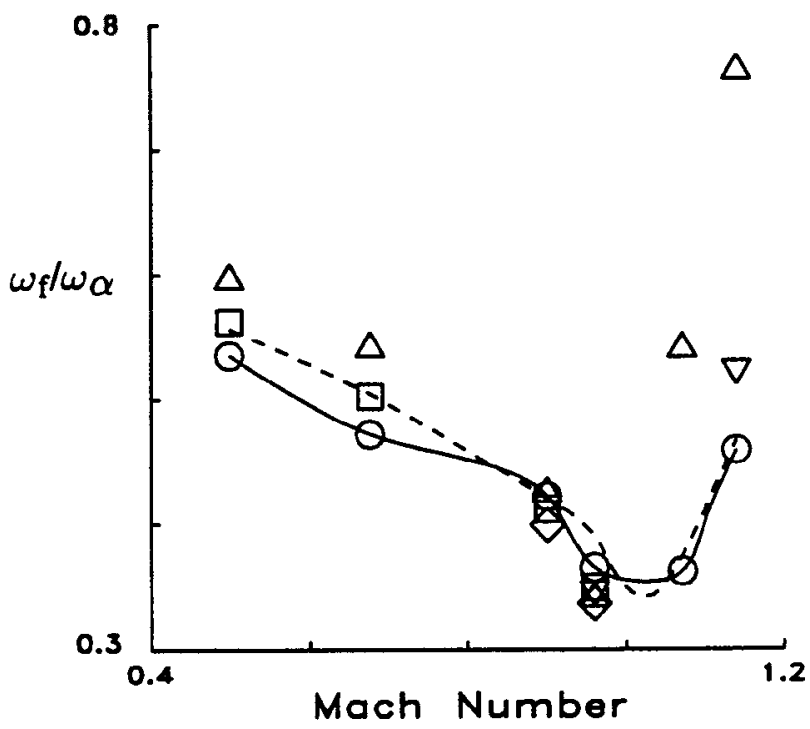

(b) Frequency ratio.

Fig. 3 Comparison between experimental and calculated flutter speed index and frequency for the AGARD Wing 445.6 tested in air.
The wings had a NACA 65A004 airfoil and were constructed of laminated mahogany. To reduce the stiffness, some wings had holes drilled through them and filled with foam. The vibration modes were calculated and are published in ref. 32 .

Fig. 3 summarizes the flutter results for the 445.6 wing tested in air in terms of the flutter speed index and frequency ratio. For these cases, the mass ratio is relatively high, $\mathrm{O}(100)$, and the reduced frequencies in the transonic range is relatively low, that is, less than 0.10. The linear theory results from CAP-TSD, as indicated by the dashed line in Fig. 3, agree quite well with the measured values except in the range of Mach numbers near 1.0 where the results are somewhat high. For this thin wing, transonic effects begin quite close to a Mach number of 1.0. Including thickness in the CAP-TSD results lowers the flutter speed slightly for the subsonic Mach numbers with the most reduction at $\mathrm{M}=0.96$. The addition of the boundary layer in CAPTSDV slightly raises the flutter speeds and they are in agreement with the experimental data. The CFL3DEuler $^{38}$ results are in good agreement at the lower two Mach numbers, but are increasingly low near $M=0.96$. The CFL3D-Navier-Stokes ${ }^{39}$ result at $\mathrm{M}=0.96$ is somewhat higher and shows improved agreement.

For supersonic speeds, the CFL3D-Euler results show a premature rise and a large overprediction of the flutter boundary. Similar results have been shown in ref 40 , and unpublished results with CAP-TSD, but the Euler results of ref. 41 are close to the experimental data. Here, the one point at $\mathrm{M}=1.14$ with CFL3D-Navier Stokes shows a large reduction of flutter speed with the inclusion of the boundary layer effects, but is still about 18 percent high in $\mathrm{V}$ (or 40 percent in dynamic pressure). Further effort is needed to investigate this sensitivity to viscous effects.

Fig. 4 presents the CAP-TSDV results for the weak wings in heavy gas. The mass ratios for these cases run from 12-34 and reduced frequency from 0.33 to 0.18 as Mach number is increased. Generally good agreement is shown in this case also. A dip calculated with CAP-TSDV is shown which occurs just before the last measured point near $M=1.0$. Reynolds number and amplitude effects were explored ${ }^{36-37}$ showing a small Reynolds number effect near the dip and a moderate effect of excitation amplitude on the boundary at Mach numbers higher than the dip. 


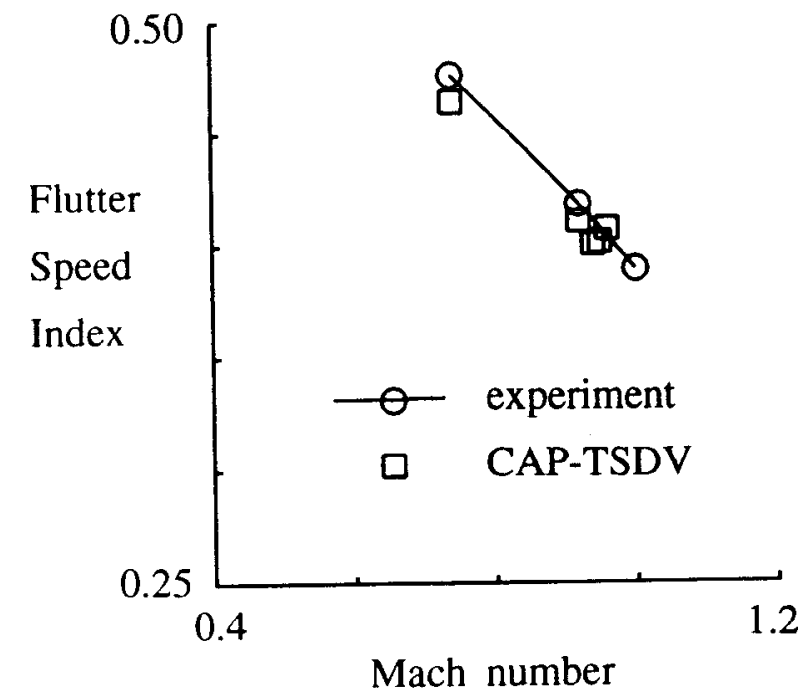

(a) Flutter speed index.

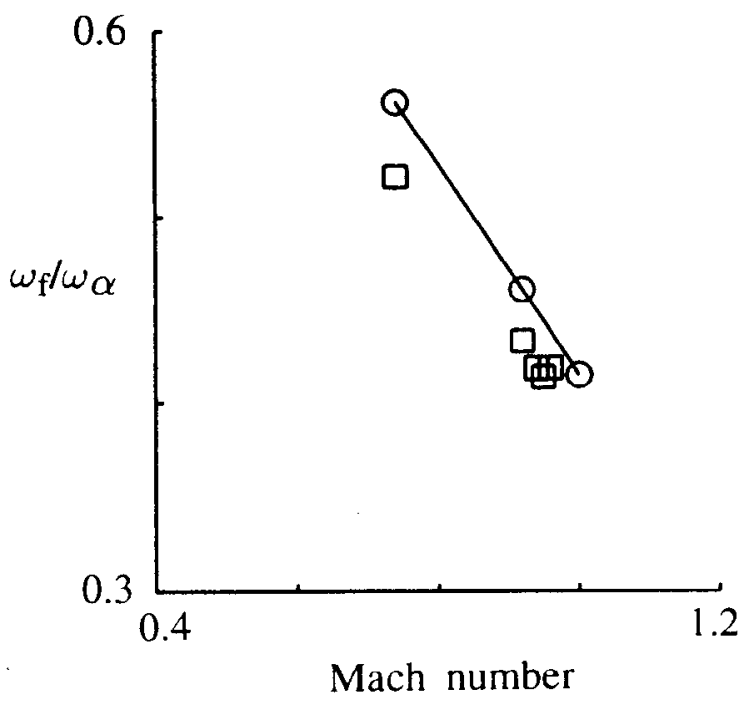

(b) Frequency ratio.

Fig. 4 Comparison between experimental and calculated flutter speed index and frequency for the AGARD Wing 445.6 tested in heavy gas.

\section{Business Jet Wing}

The business jet flutter model is shown in Fig. 5 mounted in the Transonic Dynamics Tunnel. An extensive set of flutter and static aeroelastic calculations using CAP-TSD and CFL3D-Euler and Navier-Stokes were made by Gibbons ${ }^{42}$ to compare with the measured flutter boundary. Calculations using CAP-TSDV have been presented by Edwards. $36-37$

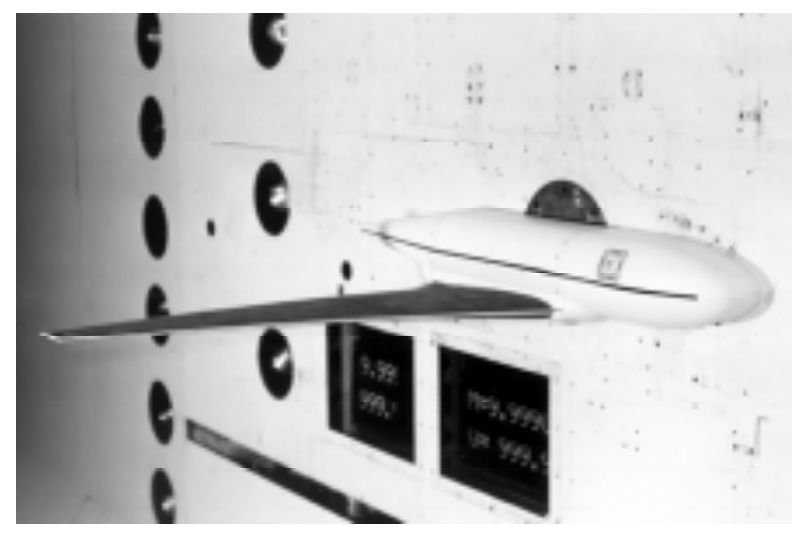

Fig. 5 Business jet flutter model mounted in NASA Langley Transonic Dynamics Tunnel.

The model was 4.4 feet in semispan and was constructed from an aluminum plate with foam and fiberglass used to provide the airfoil shape. The flexible wing and the stiff fuselage were mounted to the turntable in the wall of the tunnel. The wing root angle of attack was varied to minimize loading. The maximum angle used for this purpose was $0.2 \mathrm{deg}$ at the highest Mach number and this value was used for the CAP-TSDV calculations. This resulted in calculated static tip deflections of -1.33 in. at $M=0.628$ and +1.35 inch at $M=0.888$. The Reynolds numbers for these two Mach numbers were 2.17 and 1.14 million respectively based on the root chord of 2.0 feet for these test points in air.

The calculated and experimental flutter boundaries are presented in Fig. 6. The experimental data show only a modest dip. The point at $\mathrm{M}=0.888$ is estimated to be near the bottom of the transonic dip. Both the inviscid CAP-TSD and Euler results agree very well at the lowest Mach number but become significantly low or conservative at the highest Mach numbers. Although not shown, the linear theory calculations using CAPTSD by Gibbons ${ }^{42}$ agree very well with the measured flutter data over the Mach range tested. When viscous effects are included using CFL3D-Navier-Stokes code, the calculated flutter points are much nearer the experimental boundary, but are still somewhat 
conservative. The CAP-TSDV results are nearly the same as the CFL3D-NS results.

The above computational results are for small amplitude transient analyses. A large amplitude limit cycle oscillation was calculated for the conditions shown as the solid symbols in Fig. 6 using CAP-

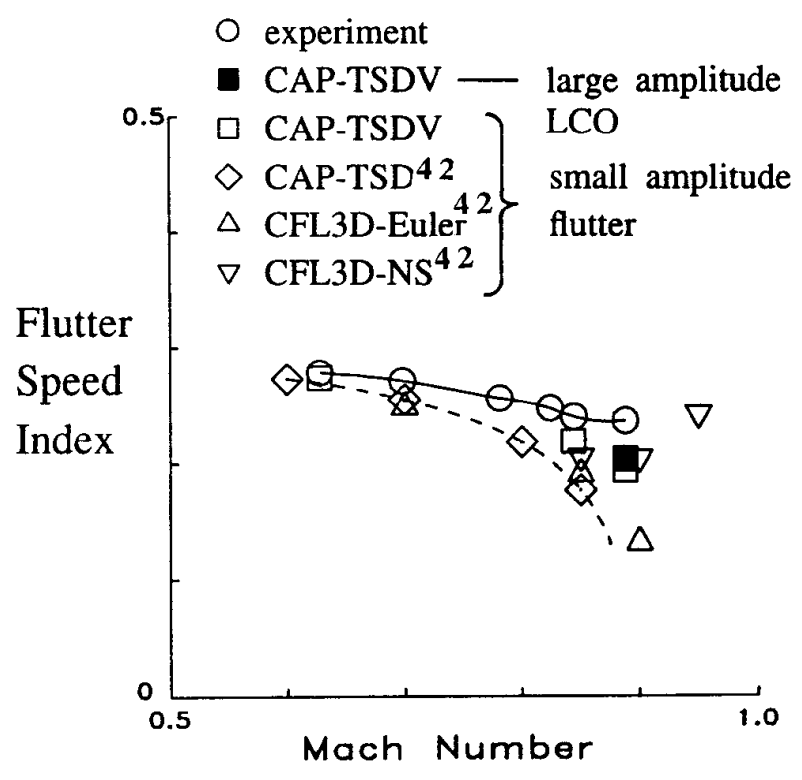

(a) Flutter speed index.

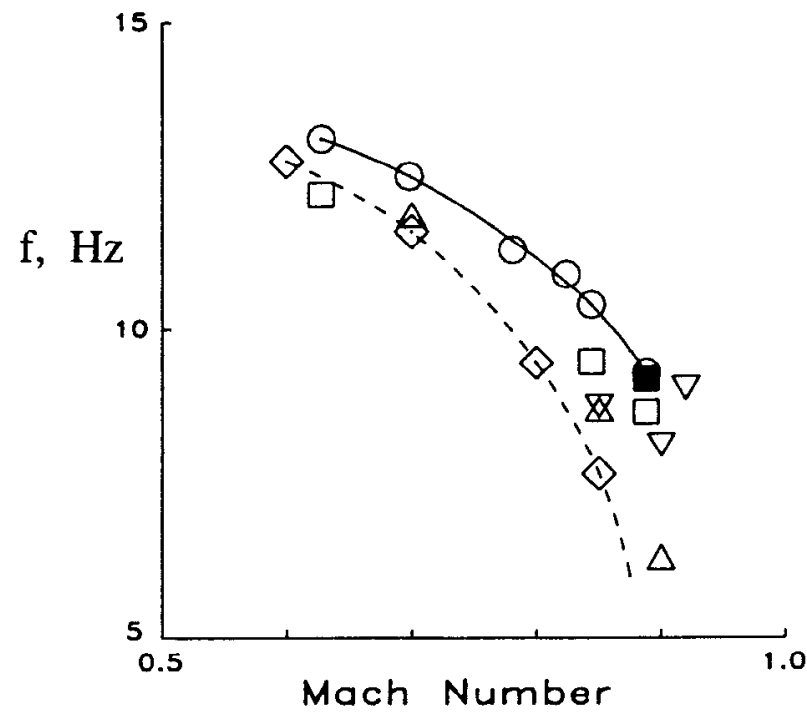

(b) Frequency.

Fig. 6 Comparison between experimental and calculated flutter speed index and frequency for a business jet flutter model tested in air.
TSDV. Fig. 7 shows two transient responses illustrating this behavior. The motions were excited from converged statically deformed conditions by multiplying the modal displacements and velocities by 5.0 for Fig. $7 \mathrm{a}$ and 0.5 for Fig. 7b. The large displacement gives a displacement of about 7 inches, which decays to about 5-6 inches peak-to-peak. The smaller initial excitation results in a similar oscillation. This is consistent with the observed flutter point at this Mach number of 0.888 . The boundary layer calculations indicated intermittently separating and reattaching flow in the outboard regions. Increasing Reynolds number in the calculations resulted in a growing oscillation that led to a larger limit cycle.

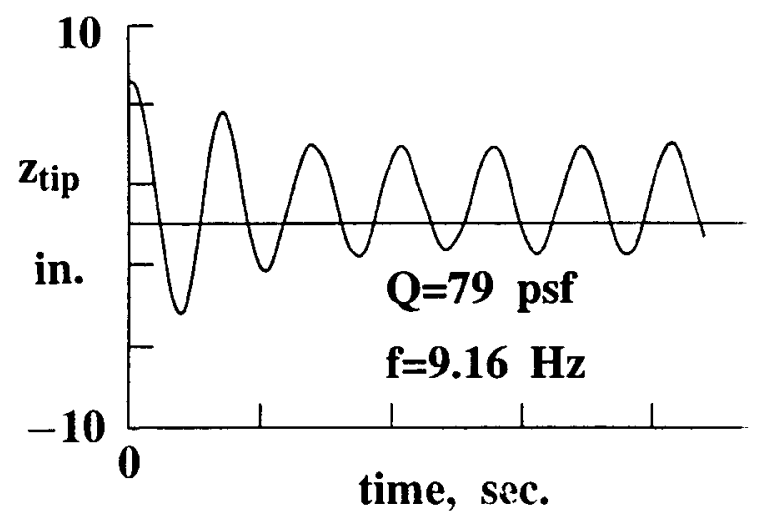

(a) Amplitude decaying to limit cycle oscillation.

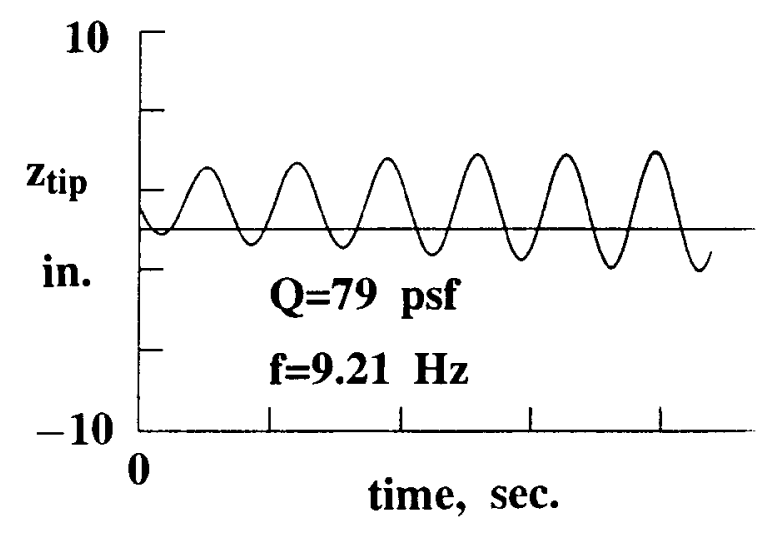

(b) Amplitude growing to limit cycle oscillation.

Fig. 7 Calculated limit cycle response for a business jet wing flutter model. $M=0.888$, $q=79$ psf, $\operatorname{Re}_{c}=1.14$ million. 


\section{Comments on Viscous Effects}

The results for the two wings discussed above have indicated strong viscous effects for some, but not all, of the cases. The 445.6 wings tested in air showed large calculated viscous effects on the backside of the flutter dip at supersonic speeds. The business jet was indicated to have large calculated viscous effects on the front side of the dip. The calculated limit cycle oscillations changed to a more divergent nature to a large limit cycle at a higher Reynolds number. Another case of viscous effects on flutter is indicated by the effect of transition strips on the flutter boundary of the Benchmark Supercritical Wing tested on the Pitch and Plunge Apparatus (PAPA) in ref. 43. The flutter boundary was raised about ten percent in dynamic pressure at low Mach numbers by adding a transition strip to the upper and lower surface of the model.

In terms of anecdotal evidence, during flutter tests of a transport model in the TDT, the approach to flutter monitored using one over peak amplitude of wing response. This parameter was approaching zero systematically as dynamic pressure was increased indicating that a flutter point was near. However, as the expected flutter point was neared, tufts showed that the flow separated near the tip, and the oscillations became more random and buffeting-like. In this case the separation, which may have been related to tip aeroelastic twist, appeared to quench flutter.

The role of viscous effects has been shown by a few isolated examples largely by inference from calculations. The generality of such effects is not yet clear. Although, it currently appears that the inclusion of viscous effects in the transonic range is essential, at least at model scale, the extrapolation of this trend to flight Reynolds Number is somewhat less certain. Current practice at the TDT is to use transition strips to assure a fixed transition location and a turbulent boundary layer. Further effort may be needed to study the best way to approximate viscous effects for flight Reynolds numbers at model scale.

\section{TRANSONIC SHOCK-BOUNDARY LAYER OSCILLATIONS}

Shock-boundary layer oscillations have been experimentally investigated for several airfoils. These oscillations are made up of separating and reattaching boundary layers coupled with moving shocks oftimes referred to as Shock-Induced-Oscillations or SIO. One notable example is the oscillations over the 18 percent circular-arc airfoil at transonic conditions and zero angle of attack. ${ }^{44}$ Several investigators ${ }^{45-47}$ have been successful in calculating this flow. Included in the successful applications is the boundary layer coupling method used in CAP-TSDV? A comparison of measured and calculated frequencies using CAP$\mathrm{TSDV}^{37}$ is shown in Fig. 8.

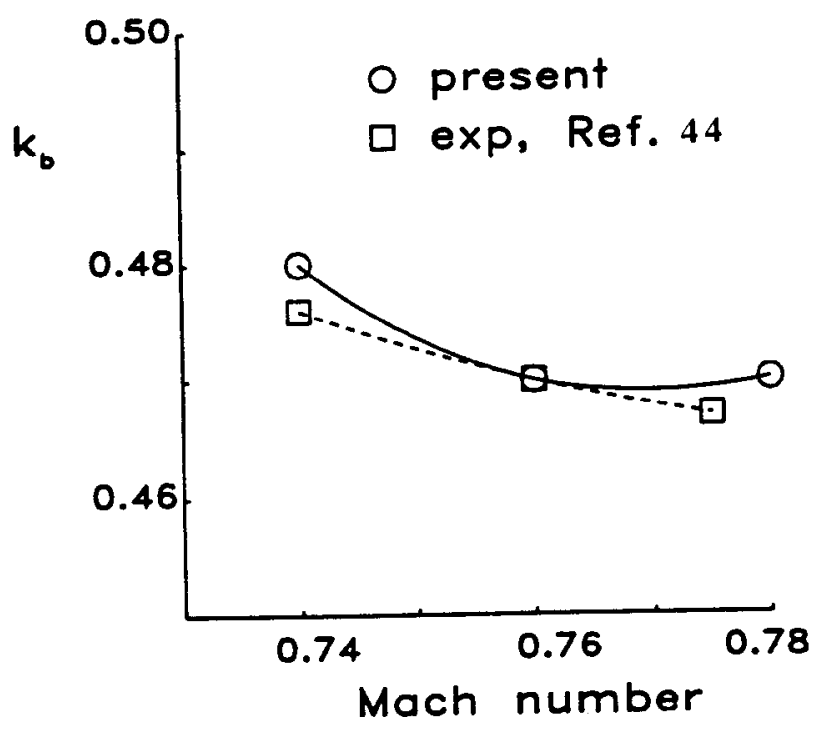

Fig. 8 Comparison of calculated and experimental SIO reduced frequencies for the $18 \%$ circular arc airfoil.

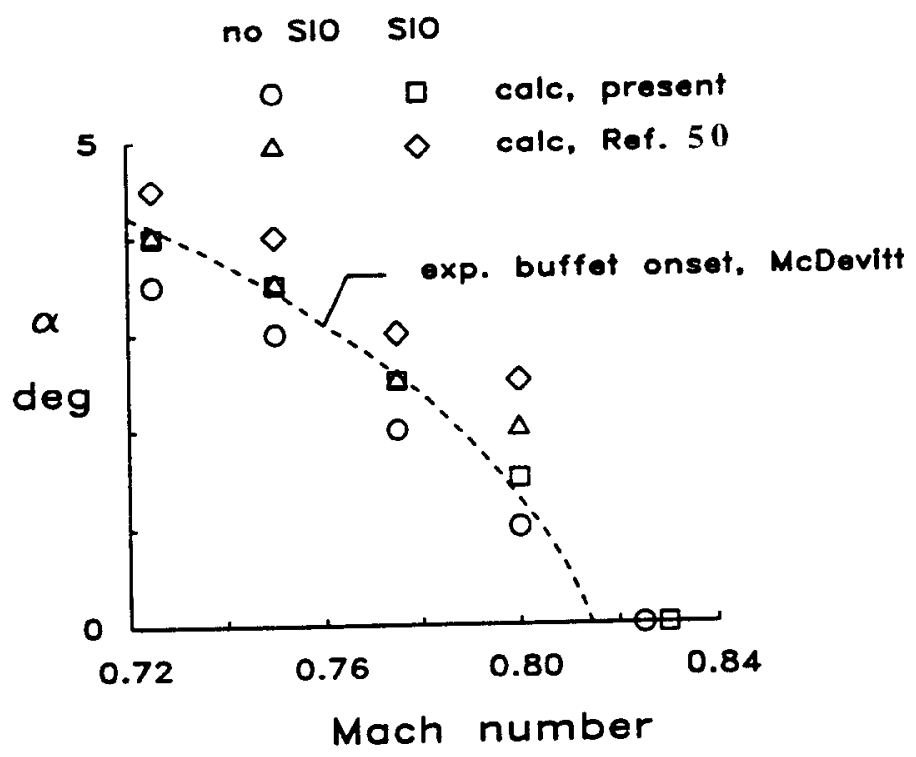

Fig. 9 Comparison of calculated and experimental buffet onset boundaries for the NACA 0012 airfoil. 
Another example is for the NACA 0012 airfoil at angle of attack ${ }^{48 .}$ Oscillations on this airfoil occur at transonic speeds and moderate angles of attack, and mostly on the upper surface. The comparison of the experimental boundary with CAP-TSDV calculations is presented in Fig. 9. There have been other successes calculating this complex flow ${ }^{47-50}$ but some higher level codes do not capture these phenomena. Other novel nonlinear features of the SIO flows calculated with CAP-TSDV are discussed by Edwards. 37

These types of oscillations can also occur on supercritical airfoils. ${ }^{51-52}$ The implications of such oscillations on three-dimensional flexible wings are not clear. One brief test indicated that for a 3-D wing, 33 the shock-boundary layer oscillations led to a buffeting condition and a low amplitude limit cycle oscillation in a higher vibration mode.

\section{CA CHALLENGES}

There are some data available that may assist in the evaluation of CA capabilities. A few are briefly discussed and involve various aerodynamic phenomena. In addition there are some difficult configurations that may need to be analyzed in the future and because of their difficulty may pose challenges to the state of the CA art.

\section{$\underline{\text { Rectangular Wings of Varying Thickness }}$}

A series of rectangular wings were tested ${ }^{53}$ to investigate the effect of thickness on flutter in the transonic speed range. The airfoil section was a simple circular arc and the series of wings varied in thickness from a flat plate to ten percent thick. Fig. 10 shows the flutter speed index for two of these wings, one with 4 percent thickness and one with 8 percent thickness. Several investigators (ref. 54-57) have calculated specific cases, but the complete trend has not been demonstrated, possibly because it is a very large computational task. It has been found that the modal data must be calculated for the wings using plate elements. The flutter boundaries are also complicated by a moderate proximity of the divergence boundary to the flutter boundary. 55

\section{$\underline{\text { Benchmark Models Data }}$}

The zero angle of attack flutter boundary for the Benchmark Model with the NACA 0012 airfoil is

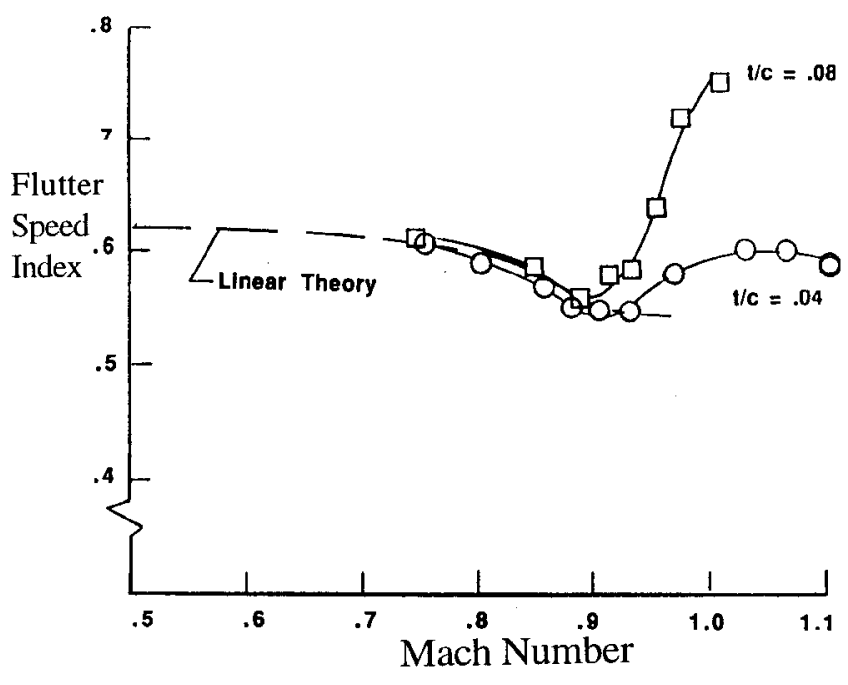

Fig. 10 Flutter boundaries for two rectangular wings with circular-arc airfoils of different thickness, ref. 53 .

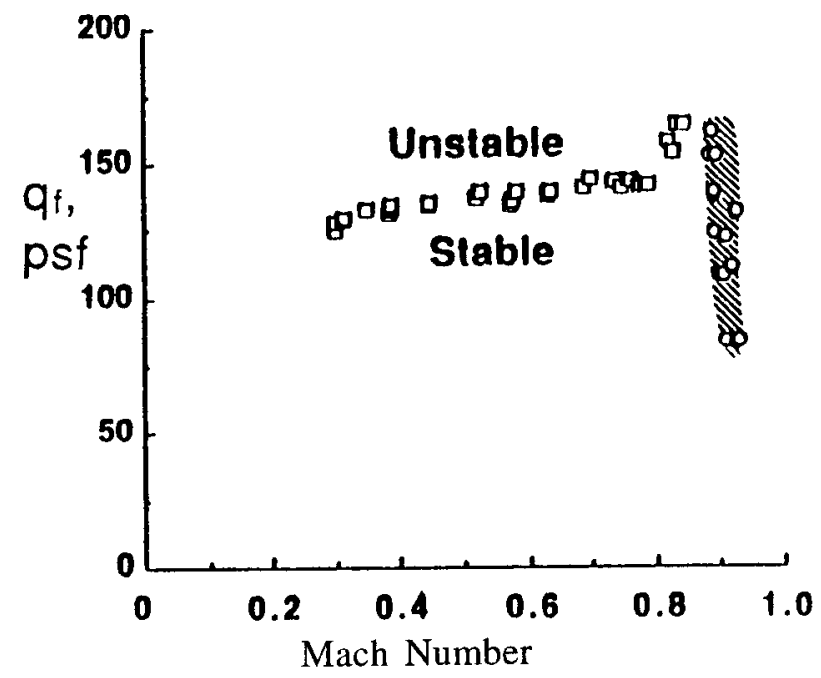

Fig. 11 Measured flutter boundaries for NACA 0012/PAPA model at zero angle of attack, ref. 58 .

shown in Fig. 11. The simple, rigid rectangular wing $^{58}$ is mounted on the Pitch and Plunge Apparatus (PAPA). The boundary to the left is the classical flutter boundary, which in this case rises with Mach number. However, near $\mathrm{M}=0.9$, there is a sharp notchlike boundary that involves mostly plunging motion. At this condition, there are strong shocks near 0.75 chord. Fig. 12 shows the boundary at $\mathrm{M}=0.78$ versus angle of attack. Above 5 degrees, the rapid decrease in 
the flutter boundary is a type of shock-induced stall flutter with the flow separating and reattaching during the cycle of motion. These cases are for very high mass ratio and some unpublished calculations have shown that the classical boundary is sensitive to aerodynamic damping of the pitching mode. Two rows of pressure measurements are available. It should be noted that the stall flutter occurs near the shockboundary layer oscillation region for the NACA 0012 airfoil.

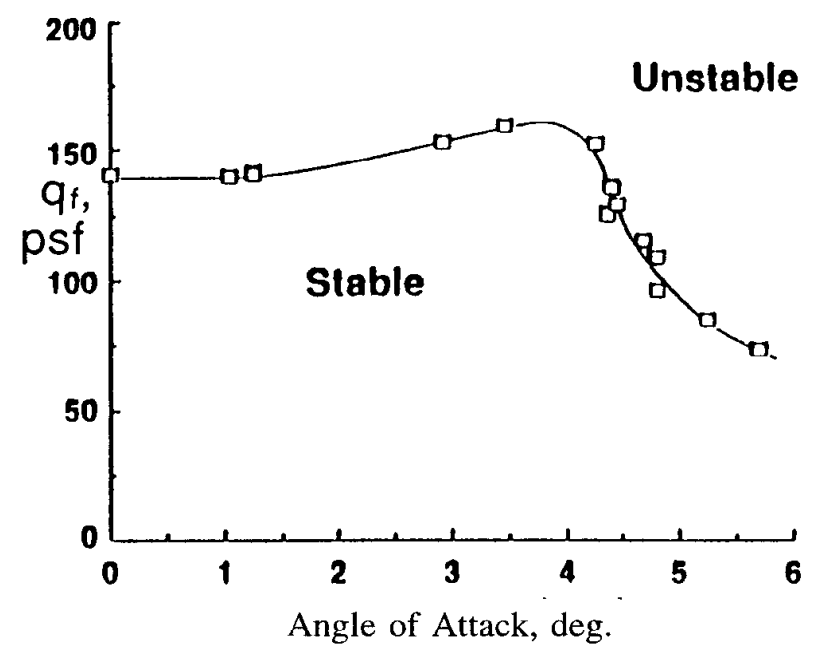

Fig. 12 Measured flutter boundary variation with angle of attack for NACA 0012/PAPA model at $M=0.78$, ref. 58 .

\section{Aeroelastic Research Wing - 2}

During the wind tunnel test of the ARW-2 wing, large dynamic oscillations were encountered at Mach numbers well above design conditions. ${ }^{59}$ Again it involved separated flows, and did not appear to be classical flutter-like or traditional buffeting. It is thought to involve movement of upper and lower surface shocks on the outer panel. The plot of 1/Amplitude is given in Fig. 13. This is an aerodynamically complex situation on a configuration that is of modest configurational complexity.

\section{Limit Cycle Oscillations}

There are several aircraft that encounter limit-cycleoscillations during flight. One semiempirical method that has had some success is described in ref. 2. The challenge is to calculate some of these cases using Computational Aeroelasticity techniques without

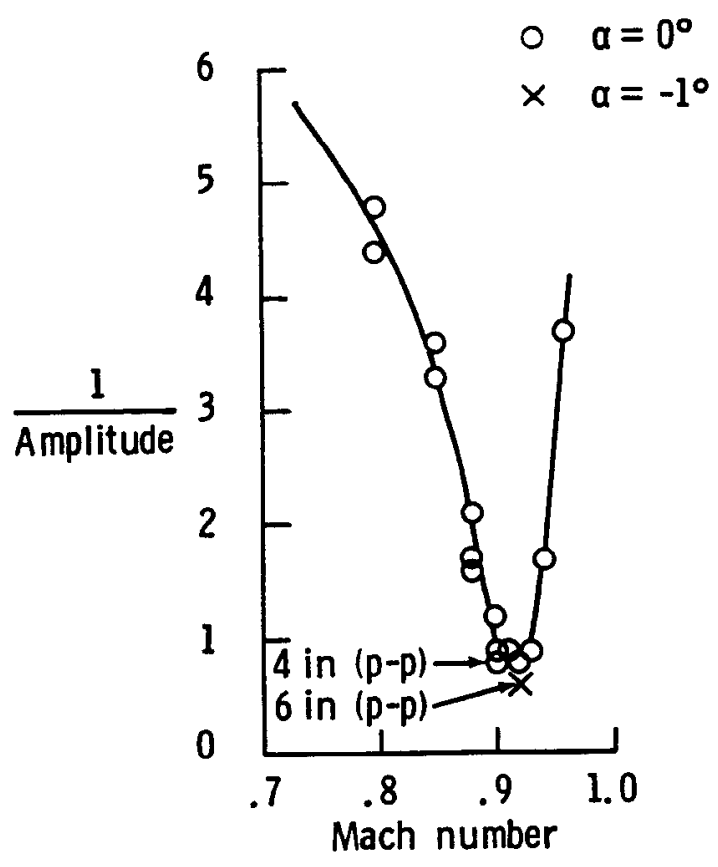

Fig. 13 Dynamic response measurements for Aeroelastic Research Wing-2, $q=260-340$ psf, ref. 59.

resorting to experiment. Another particularly notable case $^{60}$ is that of the B-2.

\section{$\underline{\text { Unusual Configurations }}$}

There are many ongoing efforts to design more efficient aircraft through innovative configurations, such as the blended wing body, joined wings, and twin fuselage transports. An example of one such study is given in ref. 61. The geometric complexity of many of these configurations will be the formidable CA challenge. Although this paper has focused on the aerodynamic effects, many of the unusual configurations will have structural dynamic challenges as well. Integrated aerodynamic controls may become an integral part of the design and will also have to be accurately treated.

\section{CONCLUDING REMARKS}

The motivation for Computational Aeroelasticity and the elements of one type of the analysis or simulation process have been briefly reviewed. The need for streamlining and improving the overall process to reduce elapsed time and improve overall accuracy is evident. Further effort is needed to establish the credibility of the methodology, obtain experience, and 
to build in experience for simplifying the method for future users.

A variety of results for two flutter cases have been discussed. Reasonable agreement is shown for the codes when viscous effects are included. There is a compelling need for a broad range of flutter test cases for further comparisons as the current test cases used for evaluation of CA are few and limited in scope. Some existing data sets should be revisited with the current generation of CFD/CA codes and further data sets are needed for calibration efforts.

Existing data sets that may offer CA challenges have been presented. These are the effect of thickness on flutter for rectangular wings with circular-arc airfoils; the classical flutter, shock-induced stall flutter, and plunge instability of the Benchmark Models wings on the pitch and plunge apparatus; and the buffet-flutter boundary for the ARW-2 wind tunnel model. Looking to the future, there will be significant challenges in calculating aeroelastic results for the many unusual configurations that are being considered.

\section{REFERENCES}

1. Henshaw, M. J. deC, McKiernan, D. D., and Mairs, C., "Flutter Prediction for Complex Configurations," Paper No. 12 in "Numerical Unsteady Aerodynamic and Aeroelastic Simulation," AGARD Report 822, March 1998.

2. Meijer, J. J., Hounjet, M. H. L., Eussen, B. J. G., and Prananta, B. B., "NLR-TUDelft Experience in Unsteady Aerodynamics and Aeroelastic Simulation," Paper No 11 in AGARD Report 822, March 1998.

3. Franzen, B., Nilsson, B., and Winzell, B., "Experience With Unsteady Aerodynamics Computations for Saab Aircraft," Paper No. 15 in "Numerical Unsteady Aerodynamic and Aeroelastic Simulation”. AGARD Report 822, March 1998.

4. Rumsey, C. L., Sanetrik, M. D., Biedron, R. T., Melson, N. D., and Parlette, E. B., "Efficiency and Accuracy of Time-Accurate Turbulent Navier-Stokes Computations," Computers and Fluids, Vol. 25, No. 2, pp. 217-236, 1996.

5. Batina, J. T., Seidel, D. A., Bland, S. R., and Bennett, R. M., "Unsteady Transonic Flow Calculations for Realistic Aircraft Configurations,"
Journal of Aircraft, Vol. 26, No. 1, Jan 1989, pp.2128.

6. Edwards, J. W., "Transonic Shock Oscillations Calculated With a New Interactive Boundary Layer Coupling Method," AIAA Paper 93-0777, Jan. 1993.

7. Schuster, D. M., Vadyak, J., and Atta, E., "Static Aeroelastic Analysis of Fighter Aircraft Using a ThreeDimensional Navier-Stokes Algorithm," Journal of Aircraft, Vol. 27, No. 9, Sept. 1990, pp. 820-825.

8 Harder, R. T., and Desmarais, R. N., "Interpolation Using Surface Splines," Journal of Aircraft, Vol. 9, No. 2, Feb. 1972, pp. 189-191.

9. Bennett, R. M., Batina, J. T., and Cunningham, H. J., "Wing-Flutter Calculations with the CAP-TSD Unsteady Transonic Small-Disturbance Program," Journal of Aircraft, vol. 26, no. 9, Sep. 1989, pp. 876882.

10. Smith, M. J., Hodges, D. H., and Cesnik, C. E. S., "An Evaluation of Computational Algorithms to Interface Between CFD and CSD Methodologies," USAF Wright Laboratories Report WL-TR-96-3055, Nov. 1995.

11. Robinson, B. A., Batina, J. T., and Yang, H. T. Y., "Aeroelastic Analysis of Wings Using the Euler Equations with a Deforming Mesh," Journal of Aircraft, vol. 28, no. 11, Nov. 1991, pp. 781-788.

12. Hartwich, P. M., and Agrawal, S., "Method for Perturbing Multiblock Patched Grids in Aeroelastic and Design Optimization Applications," AIAA Paper 972038, July 1997.

13. Bennett, R. M., and Desmarais, R. N., "Curve Fitting of Aeroelastic Transient Response Data with Exponential Functions," Flutter Testing Techniques, NASA SP-415, May 1975, pp.43-58.

14. Pak, Chan-Gi, and Friedmann, Peretz P., "A New Time-Domain Technique for Flutter Boundary Identification,” AIAA Paper 92-2102, April 1992.

15. Juang, Jer-Nan, Applied System Identification. PTR Prentice-Hall, Englewood Cliffs, NJ, 1994.

16. MATLAB ' Reference Guide, The Mathworks, Inc., Natick , MA, 1992. 
17. Silva, W. A., and Bennett, Robert M., "Application of Transonic Small Disturbance Theory to the Active Flexible Wing Model," Journal of Aircraft, Vol. 32, No 1, pp. 16-22, Jan. 1995.

18. Mehta, U. B., "Credible Computational Fluid Dynamics Simulations," AIAA Journal, Vol. 36, No. 5, May 1998, pp. 665-667.

19. Rizzi, A., and Vos, J., "Toward Establishing Credibility in Computational Fluid Dynamics Simulations," AIAA Journal, Vol. 36, No. 5, May 1998, pp. 668-675.

20. James, A., and Matronly, L., "Mesh Refinement and Modeling Errors in Flow Simulation," IAA Journal, Vol. 36, No. 5, May 1998, pp. 676-686.

21. Oberkampf, W. L., and Blottner, F. G., "Issues in Computational Fluid Dynamics Code Verification and Validation," AIAA Journal, Vol. 36, No. 5, May 1998, pp. 687-695.

22. Roach, P. J., "Verification of Codes and Calculations," AIAA Journal, Vol. 36, No. 5, May 1998, pp.696-702.

23. Habashi, W. G., Dompierre, J., Bourgault, Y., Fortin, M., and Vallet, M.-G., "Certifiable Computational Fluid Dynamics Through Mesh Optimization," AIAA Journal, Vol. 36, No. 5, May 1998, pp.703-711.

24. Yee, H. C., and Sweby, P. K., "Aspects of Numerical Uncertainties in Time Marching to Steady State Numerical Solutions," AIAA Journal, Vol. 36, No. 5, May 1998, pp.712-724.

25. Dolling, D. S., "High-Speed Turbulent Separated Flows: Consistency of Mathematical Models and flow Physics," AIAA Journal, Vol. 36, No. 5, May 1998, pp.725-732.

26. Aeschliman, D. P., and Oberkampf, W. L., "Experimental Methodology for Computational Fluid Dynamics Code Validation," AIAA Journal, Vol. 36, No. 5, May 1998, pp.733-741.

27. Reed, H. L., Haynes, T. S., and Saric, W. S., "Computational Fluid Dynamics Validation Issues in Transitional Modeling," AIAA Journal, Vol. 36, No. 5, May 1998, pp.742-751.
28. Barber, T. J., "Role of Code Validation and Certification in the Design Environment," AIAA Journal, Vol. 36, No. 5, May 1998, pp.752-758.

29. Benek, J. A., and Draft, E. M., and Lauer, R. F., "Validation Issues for Engine-Airframe Integration," AIAA Journal, Vol. 36, No. 5, May 1998, pp.759764.

30. Bobbitt, P. J.: "The Pros and Cons of Code Validation," AIAA Paper 88-2535, 1988.

31. Lambourne, N., Destuynder, R., Kienappel, K., and Roos, R.: "Comparative Measurements in Four European Wind Tunnels of the Unsteady Pressures on an Oscillating Model (The NORA Experiments)," AGARD Report No. 673, Feb. 1980.

32. Yates, E. Carson, Jr.: "AGARD Standard Aeroelastic Configurations for Dynamic Response I Wing 445.6," AGARD Report No. 765, July 1988.

33. Bennett, R. M., Eckstrom, C. V., Rivera, Jose A., Dansberry, Bryan, E., Farmer, Moses G., and Durham, Michael. H.: "The Benchmark Aeroelastic Models Program - Description and Highlights of Initial Results," Paper No. 25 in Transonic Unsteady Aerodynamics and Aeroelasticity, AGARD CP 507, March 1992.

34. "Compendium of Unsteady Aerodynamic Measurements," AGARD Report No. 702, Aug. 1982.

35. "Compendium of Unsteady Aerodynamic Measurements, Addendum No. 1," AGARD Report No. 702, May 1985.

36. Edwards, J. W.: "Calculated Viscous and Scale Effects on Transonic Aeroelasticity," Paper No. 1 in "Numerical Unsteady Aerodynamic and Aeroelastic Simulation”. AGARD Report 822, March 1998.

37. Edwards, John W.: "Transonic Shock Oscillations and Wing Flutter Calculated with an Interactive Boundary Layer Coupling Method," Paper No. 12 in Euromech-Colloquium 349, Simulation of Structure Fluid Interaction in Aeronautics, Goettingen, Germany, Sep. 16-18, 1996.

38. Lee-Rausch, E. M., and Batina, J. T.: "Wing Flutter Boundary Prediction Using Unsteady Euler Aerodynamic Method," AIAA Paper 93-1422, April 1993. 
39. Lee-Rausch, E. M., and Batina, J. T.: "Wing Flutter Computations Using an Aerodynamic Model Based on the Navier-Stokes Equations," Journal of Aircraft, vol. 33, No. 6, pp. 1139-1148, Nov-Dec 1996.

40. Farhat, C., and Lesoinne, M.: "Higher-Order Staggered and Subiteration Free Algorithms for Coupled Dynamic Aeroelasticity Problems. AIAA Paper 98-0516, Jan 1998.

41. Gupta, K., K.: "Development of a Finite Element Aeroelastic Analysis Capability," J. of Aircraft, vol. 33, no. 5, Sep.-Oct., 1996, pp. 995-1002.

42. Gibbons, Michael D.: "Aeroelastic Calculations Using CFD for a Typical Business Jet Model," NASA CR-4573, Sep. 1996.

43. Dansberry, B. E., Durham, M. H., Bennett, R. M., Rivera, J. A., Jr., Silva, W. A., Wieseman, C. D., and Turnock, D. L.: "Experimental Unsteady Pressures at Flutter on the Supercritical Wing Benchmark Model,” AIAA Paper No. 93-1592, 1993.

44. McDevitt, J. B.: "Supercritical Flow About a Thick Circular Arc Airfoil," NASA TM 78549, Jan. 1979.

45. Levy, L. L., Jr., "Experimental and Computational Steady and Unsteady Transonic Flows About a Thick Airfoil," AIAA Journal, Vol. 16, June 1978, pp. 564-572.

46. Rumsey, C. L., Sanetrik, M. D., Biedron, R. T., Melson, N. D., and Parlette, E. B.: "Efficiency and Accuracy of Time-Accurate Turbulent Navier-Stokes Computations," AIAA Paper 95-1835, June 1985.

47. Bartels, R. E.: "Flow and Turbulence Modeling and Computation of Shock Buffet Onset for Conventional and Supercritical Airfoils," NASA/TP1998-206908, Feb. 1998.

48. McDevitt, J. B., and Okuno, A. F.: "Static and Dynamic Pressure Measurements on a NACA 0012 Airfoil in the Ames High Reynolds Number Facility," NASA TP-2485, June 1985.

49. Hirose, N., and Miwa, H.: "Computational and Experimental Research on Buffet Phenomena of Transonic Airfoils," NAL TR-996T, 1988.
50. Girodroux-Lavigne, P., and LeBalleur J. C., "Time Consistent Computation of Transonic Buffet Over Airfoils," ICAS Paper No. 88.5-5.2,Sept. 1988 (ONERA TP No. 1988-97.)

51. Bartels, R. E., and Edwards, John, W.: "Cryogenic Tunnel Pressure Measurements on a Supercritical Airfoil for Several Shock Buffet Conditions," NASA TM 110272, Sept. 1997.

52. Lee, B. H. K.: “Oscillatory Shock Motion Caused by Transonic Shock Boundary Layer Interaction," AIAA Journal, Vol. 28, pp. 942-944.

53. Doggett, Robert V., Jr., Rainey, A. Gerald, and Morgan, Homer G.: "An Experimental Investigation of Aerodynamic Effects of Airfoil Thickness on Transonic Flutter Characteristics," NASA TM X-79, Nov. 1959.

54. Chen, P. C., Sarhaddi, D., and Liu, D. D.: "Transonic AIC Approach for Aeroelastic and MDO Applications," Paper No. 2 in Euromech-Colloquium 349, Simulation of Structure Fluid Interaction in Aeronautics, Goettingen, Germany, Sep. 16-18, 1996.

55. Pak, Chan-Gi, Friedmann, Peretz P., and Livne, Eli: "Transonic Adaptive Flutter Suppression Using Unsteady Time Domain Aerodynamics," AIAA Paper 91-0986, April 1991.

56. Guruswamy, G. P., Goorjian, P. M., and Tu, E. L.: "Transonic Aeroelasticity of Wings with Tip Stores," Journal of Aircraft, vol. 24, no. 10, pp. 688695, Oct. 1987.

57. Guruswamy, G. P., Goorjian, P. M.: "Unsteady Transonic Aerodynamics and Aeroelastic Calculations at Low-Supersonic Freestreams," Journal of Aircraft, vol. 25, no. 10, pp. 955-961, Oct. 1988.

58. Rivera, J. A., Dansberry, B. E., Bennett, R. M., Durham, M. H., and Silva, W. A.: "NACA 0012 Benchmark Model Experimental Flutter Results with Unsteady Pressure Distributions," AIAA Paper No. 922396, April 1992.

59. Seidel, D. A., Eckstrom, C. V., and Sandford, M. S.: "Investigation of Transonic Region of High Dynamic Response Encountered on an Elastic Supercritical Wing," AIAA Paper 87-0735, April 1987.

60. Jacobson, S., and Britt, R.: "Residual Pitch Oscillation (RPO) Flight Tests and Analysis on the B2 Bomber," AIAA Paper 98-1805, April 1998. 
61. Yaros, S. F., Sexstone, M. G., Huebner, L. D., Lamar, J. E., McKinley, R. E., Jr., Torres, A. O., Burley, C. L., Scott, R. C., and Small, W. J.: "Synergistic Airframe-Propulsion Interactions and Integrations, A White Paper Prepared by the 1996-1997 Langley Aeronautics Technical Committee," NASA/TM-1998-207644, Mar. 1998. 